\title{
"Building for the future?" Government and industry responses to the challenges of talent management in China following the GFC
}

\author{
Alan R. Nankervis \\ School of Management, Curtin University, Perth, Western Australia
}

\begin{abstract}
China suffered minimal fallout from the global financial crisis (GFC), due to its burgeoning economy and 'socialism with Chinese characteristics' political strategy. However, despite this, its industries face enormous human resource management (HRM) challenges associated with the country's rapid economic growth. Principal amongst these HRM challenges is the need to attract and retain crucial talent. It is likely that if Chinese industry is unsuccessful in these endeavours, the future economic growth of China may be stalled, resulting in more serious long-term outcomes. This paper explores these challenges together with some possible solutions and future research directions.
\end{abstract}

Key Words: China, global financial crisis (GFC), human resource management (HRM), talent attraction, talent management

\section{Introduction}

Whilst few countries in the developed world escaped the ravages of the 2008-9 global financial crisis (GFC), China was amongst a handful of nations which managed to maintain its economic growth during the period and to recover its equilibrium rapidly thereafter. By 2011, it had become the world's second largest economy, supplanting Japan. It became the dominant global manufacturer (Nankervis et al. 2012), and the biggest consumer of coal, aluminium, copper and nickel (Ferguson 2010, p. 21). Prior to the GFC, China's GDP averaged between 9.4-9.8\% on an annual basis for almost twenty five years (Holz 2005, p. 1; Ghosh 2010), 'built on a classic industrialisation pattern, moving from primary to manufacturing activities' (Ghosh 2010, p. 3). It was buttressed by highly successful government imperatives to attract foreign direct investment, primarily through joint ventures and the encouragement of wholly-owned foreign enterprises (WOFEs); the accumulation of large surpluses and international reserves; together with growing and increasingly diversified international investments (de Haan 2010, p. 72). Some researchers have pointed out the irony that the apparent strengths of the Chinese economy - its authoritarian political system which has facilitated rapid and at times difficult decision-making and its emphasis on investments - may also have made it more vulnerable to the effects of the GFC (Huang 2008, pp. 40, 46). 
These strengths undoubtedly insulated China from the worst effects of the GFC. They represent the outcomes of conscious central government policies and plans - 'a strong commitment to growth, productivity, competition and the privatization of property and the market, in the absence of a commitment to social equality and welfare' (Nankervis et al. 2012). The advantages of capitalism 'with Chinese characteristics' reside in its 'bridled' rather than unbridled form which have allowed the central government to guide and control the economy more effectively than its Western counterparts.

However, it would be simplistic to suggest that China was unaffected by the GFC. Some observers noted that the GFC 'very quickly had adverse effects on manufacturing exports' (Ghosh 2010, p. 4) as a consequence of China's 'high export-high accumulation' business model which made it susceptible to global economic fluctuations. As illustrations of the flow-on effects suggested, there was an almost immediate "visible impact on employment' with thousands of factory closures and twenty million jobs lost in 2008, and by June 2009 more than four million rural migrant workers were unemployed (de Haan 2010, pp. 70, 75). Associated increases in social unrest were also evident.

More recent imperatives, encapsulated in the concept of the 'harmonious society' which derives from both Chinese cultural traditions and socialist ideology, have been promulgated primarily in order to counter the more pernicious social effects of economic growth and to forestall any likely social or industrial disorder (de Haan 2010; Warner and Zhu 2010). These cultural traditions, including Confucian notions of social harmony and unity, defined as 'the co-existence of heterogeneous factors, (and) the fusion of such heterogeneity' (Huang 2008, p. 10); opposition to internal and external conflict, paternalism, and holistic views of relationships (Nankervis et al. 2012); are complemented by socialist imperatives such as social justice, the redistribution of wealth, and egalitarianism; much of which had been fractured with the dismantling of the former state-owned enterprises (SOEs) during the 1970s. As such, these recent initiatives of the Chinese government represent an attempt to restore the perceived social equilibrium of 
the past era within the new context of globalization and marketisation. As Warner and Rowley (2010, p. 275) have suggested, 'this search for harmony, built on Chinese cultural values, represents what amounts to what can be conceptualized as a "coping mechanism" to deal with the existing and potential conflicts now facing Chinese society'.

In this vein, the government reacted quickly and effectively in response to the adverse effects of the GFC, reflecting both long-and shorter-term imperatives - 'building for the future'. Its US\$590 billion stimulus package (EIU 2010, p. 4) represented a significant shift from its former export focus towards 'an inward-oriented model (which provided) more egalitarian social services, accompanied by drastic institutional changes, notably in health and social security provisions' (de Haan 2010, p. 70). More specifically, government agencies urged employers to avoid employee retrenchments; provided significant business tax reductions, changes in VAT rebates, credit flexibility, subsidies to consumers (for example, vouchers for appliances, furniture and cars - EIU 2010, p. 4); and implemented measures intended to stabilise housing and stock markets (de Haan 2010 , p. 75). In summary, the outcomes of these initiatives were twofold - first, to balance its former export focus with a complementary emphasis on internal economic development; and secondly, to ensure China's place in the global economy. To date, both appear to have been largely successful, and have the capacity to remediate not only the adverse effects of the GFC, but also to partially address the emerging challenges presented by China's changing demographic and consumer characteristics.

\section{Research propositions}

This paper explores the contradictory challenges posed by China's successful recovery from the GFC due to its cultural, ideological, and economic characteristics in contrast with its vulnerability to the longer-term consequences of its rapid economic growth, namely talent attraction and retention. The underpinning propositions include the following, that:

1. Whilst the GFC adversely affected the Chinese economy, its consequences were less significant than those in many other economies, and its recovery was considerably more 
rapid than its Western counterparts, due to its 'capitalism with Chinese characteristics' philosophy and the crucial role of the Chinese government;

2. China's strong cultural and economic traditions were central to its recovery from the GFC; and

3. Its long-term orientation is both an advantage, and a potential weakness, with respect to its ability to address the talent management challenges it faces as a consequence of its global success.

This paper analyses the contemporary context and challenges faced by the Chinese government and industry with respect to the global issue of talent management, at both the macro- and micro-management levels. It combines a review of the current literature, together with evidence from several case studies, in order to explore these issues.

\section{The changing landscape - demographics, consumerism, and their consequences}

The aging of the population, increasing urbanization, the development of a sizable middle class, and a growing associated gap between rural and urban incomes and quality of life, are well known features in the mosaic of modern China. In the latter case, whilst a significant program of poverty reduction has been undertaken over the last two decades, China's Gini coefficient indicates that new forms of inequality consequent on economic growth have arisen (Chen and Miller 2010, p. 24; Ghosh 2010; Warner and Zhu 2010, p. 286), principally between the employed and the unemployed, and between those with limited skills and the highly talented.

This paper focuses on the particular dilemmas presented to the Chinese government and industry managers with respect to the attraction and retention of necessary talent to progress its future economic growth, in the context of its changing population and labour market. Subsequent sections of the paper explore the depth of the problem and some of the solutions which government and industry are pursuing in order to address the pertinent issues. 
A recent Economist report on the 'wants and worries' of Chinese consumers provided some interesting and relevant information on the aspirations of the growing middle class, from which most local talent is necessarily sourced (EIU 2010). The report found a high degree of optimism (91\%) amongst the 2,651 participants, with a strong consumerist focus (cars, property, refrigerators, washing machines, mobile telephones), and modern Western-style demands (more comfort, more space, more privacy - EIU 2010, p. 14). Their concerns were found to reflect many of those expressed by their global counterparts, including pollution, traffic, public security and finances -'financial insecurity is a theme that underpins all the other concerns' (EIU 2010, p. 32). Financial security is closely linked to job security, which has become more problematic with China's economic growth, technological developments and the continuing global fluctuations. As the report itself indicated, 'the number of university graduates (estimated at 6.3 million in 2010) now exceeds that of entry-level jobs...there are now so many university graduates looking for a job in big cities like Shanghai and Beijing that the recent graduates are known collectively as the "ant Tribe"'(EIU 2010, p. 22).

The remarkable economic growth of China, buttressed by its cultural and ideological traditions and the central role of its government, and perhaps best illustrated by it almost singular capacity to ride out the GFC, now presents it with enormous challenges to maintain the momentum in the face of dynamic national and global industry environments. Foremost amongst these challenges is the identification, nurturing, and retention of talented employees who will be able to provide Chinese government and industry with the required professional, technical and managerial capabilities necessary for future economic development. All of their reputed long-term planning strategies and skills will undoubtedly be tested in facing this new conundrum.

\section{Talent management}

'Talent management' has become a generally accepted term in contemporary business, encompassing the attraction and retention of the 'best' employees possessing specialist skills, abilities, and capabilities, in order to meet industry needs in a dynamic and 
increasingly competitive global environment. Coined by Michaels et al. (2001), the socalled 'war for talent' is often regarded as the primary human resource management (HRM) issue for all global organizations. McKinsey \& Company defined 'talent' as 'the sum of a person's abilities...his or her intrinsic gifts, skills, knowledge, experience, intelligence, judgment, attitude, character and drive. It also includes his or her ability to learn and grow' (Michaels et al. 2001, p. xii). More simply, Ulrich (Beechler and Woodward 2009, p. 274) proposed that it equated to the combination of 'competence, commitment and contribution'.

The factors which have highlighted the importance of, and the need for, talent identification and management are various, but all are associated with globalization, increasing competition, and industry restructuring. On the demand side, most authors agree that the operations of multinational corporations require more sophisticated professional and managerial experience and that the growth of international mergers and acquisitions both reduce the required numbers of employees and increase their skills expectations while new technologies demand ongoing employee flexibilities (Bradford 2007; Bhatnagar 2008; Beechler and Woodward 2009; Schuler et al. 2010). With respect to the supply of talent, the determining variables include: demographic trends (aging populations, declining birthrates, diversity; and generational issues, notably associated with Gen Y); the quantity and quality of education systems; and (national and international) employee mobility patterns (Bhatnagar 2008; Beechler and Woodward 2009; Schuler et al. 2010).

Talent management focuses primarily on nurturing the workforce 'stars' (managerial and/or professional/technical staff), with a distinctive elitist emphasis, and utilizes the broad repertoire of HRM functions (for example, specialist HR planning, job design, recruitment, rewards and career management) to achieve its aims. Stahl et al. (2007, p. 195) define talent management as 'an emerging business strategy that enables an organization to identify, develop and redeploy key talented employees'.

\section{China's talent challenges}


Informed observers generally agree that China's future economic growth is likely to be constrained by a serious shortage of technical and professional specialists, notably in information technology, financial services and accounting occupations, real estate and construction, legal and management consulting, and in regional areas; as well as experienced senior managers with global mindsets (see for example, Pan and Lou 2004; Warner and Zhu 2010; Downing et al. 2008; Rowley and Warner 2010; Cooke 2010, 2012). In the context that 'multinationals expect about $70 \%$ of the world's growth over the next few years to come from emerging markets, with $40 \%$ coming from just two countries, China and India' (Wooldridge 2010, p. 16), this challenge has important implications globally, as well as for China itself. As Iwasaki (2010, p. 34) suggested, many of China's 'strategic overseas operations are often constrained by a shortage of human resources with adequate international experience'. Changes to Chinese accounting and auditing standards during 2006 demanded more than 300,000 new qualified accountants, although only 25,000 graduate annually. These shortfalls are most pronounced in multinational companies operating in China, but are also present in many of the modernizing state-owned enterprises and local private companies. In addition, as Bhatnagar (2008, p. 19) explained, 'a small number of booming mega-regions like Shanghai, Beijing and Guangzhou are sucking talent from the countryside'. As evidence of the scope of the overall problem, a McKinsey \& Company study (Farrell and Grant 2005) predicted that Chinese companies would require some 75,000 additional managers during the next decade; China Academy of Social Science researchers reported that 25 million new jobs were created in 2010 alone (Sainsbury 2011, p. 34); Manpower research estimated that forty percent of employers in China could not fill senior management positions (Arkless 2007); and a later study not only confirmed these estimates, but further suggested that the problem was being compounded by extremely high attrition rates (more that 25 percent higher than the global average) and associated replacement costs (between 300-2000 percent of the departing managers' salary packages (Downing, et al. 2008, p. 2).

Apart from demographic issues, and the gap between talent demand and supply, there are also significant challenges associated with the quality and expectations of the 
available labour markets. Despite the enormous growth in higher education institutions and both formal and informal management programs over the last decade, supported by the national government, 4.79 million undergraduate and postgraduate students graduated in 2007, 1.68 million in management disciplines, together with the return of some 44,000 overseas-trained graduates (China Statistical Yearbook 2008, cited in Cooke 2010, p. 254), many potential employers felt that there was 'a significant gap between what they seek and what overseas-trained Chinese graduates (as well as home students) possess' (Rowley and Cooke 2009, p. 256). Deficiencies identified included: a serious lack of work experience; limited knowledge of the European and American legal and administrative systems; an inability to deal with the financial aspects of mergers and acquisitions; inadequate English fluency and overall oral skills, a lack of leadership competencies (Downing et al. 2008), undeveloped innovative and creative capacities, and importantly, poor analytical skills. Downing et al. (2008, p. 2) assert that less than ten percent of these overseas- or home-grown Chinese graduates possess appropriate managerial skills. Thus, 'China's next generation of college graduates are not prepared for new ways of doing business' (ibid), notably at the global level. As Downing et al. (2008) report, only the top 20 percent of available talent (from the diverse labour pools of non-Chinese expatriates, ethnic Chinese regional expatriates, mainland Chinese returnees, and local graduates) are seriously considered for managerial roles (Downing et al. 2008, p. 8).

Another looming problem is the so-called 'expectation mentality' nurtured inadvertently by the 'one-child policy' (Chatterjee and Nankervis 2007; Cai and Klyushina 2009; Rowley and Warner 2010; Rowley and Cooke 2011, p. 256) - the socalled 'little emperor syndrome', which is likely to only exacerbate Generation Y attitudes towards work, careers and rewards. Certainly, in common with their counterparts in developed economies, China's new generation of graduates are highly techno-savvy and exceedingly well-networked when it comes to applying for jobs. For example, 'candidates are so closely networked that they alert each other so that they can use counter offers to their advantage' (Downing et al. 2008, p. 11). This may also help to account for the significant job-hopping which occurs in the larger Chinese cities and 
economic zones, especially from state-owned enterprises to foreign multinational companies, and the increasing diminution of loyalty from such employees (Cai and Klyushina 2009, p. 8), as well as the growing 'compensation creep'.

As evidence of the latter trend, some research studies suggest that base salaries for Chinese professionals have increased by up to 33 percent in recent years, and that around a third of skilled employees increased their salary packages by more than half when moving from one multinational company to another (Downing et al. 2008, p. 6). In cities such as Beijing, Shanghai and Guangzhou salary rate rises reportedly rose annually by 7 9 percent, and between 7.5 - 10.6 percent in some other economic zones (Downing et al. 2008 , p. 7). However, as some recent research indicates 'only the people over 40 years of age care about benefits and need a stable income. The Chinese (applicants) below 35 years of age expect to be paid well, but have low needs for benefits' (Cai and Klyushina 2009, p. 39).

Cooke's (2010) research in China indicates that traditional values coexist with newer aspirations for individual recognition, financial rewards and benefits, career advancement, and material possessions. She further suggests that younger Chinese professionals and managers appear less risk-aversive and more receptive to traditional Western extrinsic motivators than their older colleagues (p. 262). These findings are supported by a recent study of thirty senior managers in multinational companies in Qingdao which concluded that such employees are more prepared to accept performancerelated pay, are more comfortable with risk-taking behaviours and the 'subjugation of traditional Confucian culture to material gain' (Ananthram 2011, p. 5)

\section{Chinese government and industry responses to talent management challenges}

\subsection{Government responses}

Partly in response to the talent management challenges discussed previously, the central government has recently reviewed the policy and regulatory components of the Chinese 
vocational training system, with respect to the links between pre-employment training, on-the-job training, re-employment and entrepreneurial training. The review's recommendations included: the establishment of a vocational skills training system which focuses on three principles - namely, extended coverage of trainees (especially in rural areas); multiple levels of training (as above), and a plethora of training providers. The new system will include vocational subsidies to employee groups under a Special Vocational Training Program; entrepreneur-school cooperation; vocational skills assessment; and a national vocational classification code. A recent Organisation for Economic Cooperation and Development (OECD) report praised many elements of these changes, but also noted some continuing challenges, such as inconsistent cooperation in such programs by employers, variable school-based resources and inadequate training quality standards. For example, Kuczera and Field (2010, p. 5) state 'there are few quality standards for workplace training and few regional, sectoral or national bodies to engage employers and link them to the VET (vocational, education and training) system', and 'insufficient' workforce planning systems.

Many Chinese private and government-owned organizations have chosen to outsource their talent attraction activities, as the country's impressive growth has not been matched by a sufficient supply of skilled specialists, thus exerting enormous pressure on many employers - 'these challenges (have been) met by outsourcing part of, or the entire hiring process, to a third-party to enjoy lower hiring costs, higher productivity, and business efficiency' (Downing et al. 2008, p. 17). Conversely, there is considerable evidence of talent poaching amongst those companies which are able to offer more competitive reward packages or career opportunities. However, there is also limited but encouraging evidence from China that some large companies, both local and foreign, are actively attempting to adopt a strategic approach to their crucial talent management dilemmas (Anonymous 2005; Warner and Goodall 2010; Rowley and Cooke 2011). These include, the sophisticated strategies employed by foreign multinational corporations such Microsoft China, which 'grooms talent, rotates staff from (its) headquarters and creates a workplace environment which ensures that employees 
feel valued and are highly engaged in their work' (Bradford 2007, p. 2), including through the development of succession plans for technical and managerial staff.

\subsection{Foreign $M N C$ responses}

Foreign multinational corporations aggressively use their well-established global brands and word-of-mouth reputations as the primary means of attracting and retaining talent in China, successfully appealing to the ambitions and desires of creative younger applicants. As an example, Microsoft has exported many of its US talent development programs to its Chinese operations. These include special training for program managers, knowledge transfer from its headquarters, and global employee rotation programs called the Marco Polo Program and the Silk Road Scholar (Bradford 2007, p. 3). Atlas Copco uses a combination of job rotation, coaching, action and e-learning, self-directed-learning and in-house university qualifications, mentoring and coaching (Cai and Klyushina 2009, p. 50); Motorola provides localised management development programs (Cooke 2010, p. 270); and Electrolux employs succession planning, Intranet training, team-building schemes, and mentoring techniques for such purposes (ibid). The above examples reflect the export by US multinationals of relatively standardized talent development and retention practices to their subsidiaries in China, although they are by no means as common in their smaller foreign counterparts.

\subsection{Chinese $M N C$ responses}

A recent study of senior local managers (Ananthram 2011) found that many Chinese organizations are adopting more objective Western HRM techniques for talent recruitment, selection and promotion, including national advertising, structured selection interviews, promotional criteria such as professionalism and competence, and selective rewards programs, together with more traditional approaches such as network-based recruiting and 'annual red packages' (p. 10). Lenovo, for example, has an extensive university recruitment campaign, involving an innovative website, external recruitment agents, and frequent job fairs, under the umbrella of its 'Lenovo Campus Program' (Chen 2006, p. 40; Selvaretnam 2011). Beechler and Woodward (2009, p. 279) have suggested that 'innovative, integrative and strategic responses (are necessary) to create more 
cooperative and generative talent approaches', and are likely to encompass new sources of talent and the 'reverse' mentoring of older employees by younger employees, maximizing the benefits of the increased diversity of labour markets and 'career customization'.

The following section highlights the talent management strategies and techniques employed by three of the largest and best known Chinese MNCs - namely, Haier, Huawei and Lenovo. All have become 'global players' in their respective markets in recent years, and all employ local and overseas production and HR professionals; they utilize comprehensive research and development (R\&D) activities; integrated human resource development programs; and achieve enviable sales revenues. Some of their success can be attributed to the 'enduring role of government' (Cooke 2012b, p. 3) which buttresses their economic position, and close links with the military and key government authorities (for example, the Ministry of State Security) which have facilitated their business activities.

Haier has an ambitious business vision - 'creating resources and worldwide prestige' (Yidan 2009). It embraces innovation, a strong customer focus, 'fashion and personalization' and claims concern for its environmental impact. Its strengths are said to focus on its technological capabilities, corporate culture, global integration, spirit of innovation, central management control system, and high quality service. It employs 'a holistic system, aligning every HR activity from recruitment to performance management to the company's business strategy pursuing a relentless focus on growth, quality and innovation' (Xin and Pucik 2006, p. 2). These authors also suggest that it values transparency and fairness in its HRM systems, and that it consciously targets potential employees whose values are aligned with those of the company (Zhao 2005; Xin and Pucik 2006), a crucial element of its 'holistic' system. Therefore, 'while we present our enterprise's objectives, we can offer each individual a developing space to realize his (sic) own value' (Haier 2009). 
These objectives are achieved through the public recognition of individual employees, constant performance monitoring, high employee motivation, and (perhaps contradictorily) the regular culling of poor performers (through the 'Elimination Quota'). In order to achieve its HRM objectives, Haier's reward strategy includes management and employee stock options, performance-based bonuses based on overall annual output, and separate career paths for administrators, professionals and workers (Liu 2010, p. 120). Its 'racetrack' model of career development is based on backing winners and eliminating losers. It is based upon the premise that 'each promotion means another race starts. The opportunities and talent pool are open. Whoever has the talent and capabilities and can produce results, will be recognized and rewarded' (Xin and Pucik, 2006). Expressed somewhat differently, Huawei's HRM vision is 'internationalization through localization' (Cooke 2012, p. 22), promoted thus:

\begin{abstract}
'dedicated and passionate employees are Huawei's most valuable asset. In recognition of their contributions, Huawei has established policies to ensure that employees are given growth opportunities and competitive remuneration. We attach high importance to employees' mental and physical health. By providing a complete Employee Health Security System, a wide range of leisure activities, and open communication channels, Huawei makes every effort to facilitate staff recognition and ensure employees' personal growth is realized alongside Huawei's success' (Huawei 2011).
\end{abstract}

Nacsa (2011, p. 3) explained that Huawei 'undertakes management transformation benchmarked against industry best practice'. Thus, its HRM principles incorporate ethical standards, job satisfaction, integrated learning opportunities, dual career paths (managerial and professional), competitive remuneration, employee mentoring, and (limited) employee consultation (Huawei 2011). Its human resource development (HRD) program encompasses both technical and management training, together with opportunities for selflearning (Huawei School Online), coaching and tutoring, and it has an 'employee training ladder' linked to its career development system (Liu 2010, p. 126). This 'training ladder' encompasses integrated new staff; management; technical; marketing and sales; professional and production programs (Liu 2010, p. 127).

Lenovo is unique amongst Chinese MNCs in its 'people first' philosophy - 'creating space to develop employees, upgrading their value, and improving their working and living quality' (Teagarden and Cai 2009, p. 74). Lenovo's HRM rhetoric includes the 
nurturing of 'innovative, creative people; relationships that are respectful; leaders who inspire; and meaningful work' (Lenovo 2011a). Thus, the firm focuses on talent attraction and retention - 'individuals who are diverse, flexible, highly-skilled and motivated; who understand how their work contributes to the bottom-line success of the company; and who demonstrate dedication to their customers - both internally and externally' (ibid). Nevertheless, the HRM priority appears to be 'talent management'. A 'Mobility Plan', with the intention of management development through global relocation has been implemented at the international level, "we have very focused development programs in which our top talents take up short and medium term assignments in other countries' (VP Human Resources, cited in Bradford 2007: 1).

Lenovo also conducts an associated Accelerated Leadership Program for HiPotentials in ASEAN (ALPHA) which combines talent mapping with individual development plans, coaching and mentoring schemes (Selvaretnam 2011, p. 2). Lenovo has also developed its own 'university'; conducts staged programs which integrate induction, general technical, professional and managerial training (Chen 2006, p. 44; Liu 2010); and presents a 'Women in Lenovo Leadership (WILL)' course (Lenovo 2010b). Its reward strategy is similar to those in other global companies, and encompasses employee share options, annual bonuses to 'exceptional' employees based upon the company's (and their business unit's) financial performance, together with additional profit-sharing and discretionary bonuses, These are complemented by full medical coverage for all Lenovo employees and their dependants (including same-sex partners); Lenovo Flex, which offers additional dental and eye care services, life and disability insurance; and vacation leave entitlements. Whilst these latter initiatives are relatively common in foreign MNCs, Lenovo is a market leader amongst its indigenous counterparts in the scope and breadth of such employee benefits. Neither Haier nor Huawei currently match them, although it is likely that competition for talent will force them to implement similar programs in the foreseeable future.

In summary, all three Chinese MNCs have adopted sophisticated Western-style talent attraction and retention strategies, including integrated employee recognition, human 
resource development, remuneration and career development schemes, to their considerable advantage in maintaining creative and innovative workforces. However, each company's practices are customized to their particular cultures, and reflect their esoteric interpretations of these HRM techniques. There is evidence of underlying unitarism ideologies and paternalist management styles in Haier and Huawei in particular, and potential internal inconsistencies amongst some of their practices (for example, Haier's 'race track' career development and its 'elimination quota'; Huawei's reputation for excessive work demands - Cai and Klyushina 2009; Cooke 2010).

\subsection{Chinese SME responses}

Literature on local Chinese small and medium enterprise (SME) approaches to talent attraction is not readily available, although Cooke (2010, p. 260) provides some interesting insights. She suggests that, contrary to perceptions, financial rewards, career opportunities, the satisfaction of employees' needs for recognition and esteem, and benefit packages (in that order), are strong determinants of employee retention (Leininger 2007, p. 28). In addition, a small number of local Chinese companies have graduate management trainee programs, whilst ZTE (amongst others) promotes it employee benefits, mentoring and career development opportunities in addition to its training and development academy (Cooke 2010, pp. 269-70).

Given the depth of the present and future talent shortages in China, it is not surprising that multinationals, local companies and government departments have adopted a range of techniques for their attraction and retention, combining traditional with more modern approaches. Thus, together with the provision of competitive rewards and benefits packages, leadership development, continual learning and structured career development opportunities (Bradford 2007), coaching and mentoring as well as the outsourcing of peripheral functions, many organizations have adapted their selection systems to access available technologies, and to more closely match the expectations and communication styles of new generation applicants. Thus, techniques such as applicant-friendly company websites, online screening and testing systems, and comprehensive human resource management databases are utilized by some Chinese companies in order to access internal, 
as well as 'smart' business addresses and global relocation opportunities for external, labour markets.

More sophisticated talent management techniques are generally restricted to foreign multinationals and a small number of Chinese global corporations such as Huawei, Haier, and Lenovo, as discussed earlier. Inter alia, they include career-focused competency frameworks, comprehensive talent assessments, the identification of critical organizational roles; together with challenging job assignments, higher education sponsorships and executive coaching (Sharma and Bhatnagar 2009). With respect to talent assessments, a study of 437 organizations by Chen (2006: 20) found that only six percent used Westernstyle assessment centres, which some authors (Chen 2006, p. 22) have suggested have 'questionable cross-cultural validity'. Others have sought to lure skilled applicants from the diaspora ('haigni', or 'sea turtles' in Chinese) with varying degrees of success, or to consciously seek a blend of expatriates and locals.

\section{Conclusion}

It is clear that, whilst the Chinese economy was not as severely impacted by the GFC as were the economies in many developed Western nations, due to the combination of its governmental strategies and policies; its risk aversive and diversified investments, traditional long-term planning orientation, and in particular, its rapid and apparently effective stimulus package, there were significant adverse effects on Chinese industries and their employment opportunities. As discussed earlier in the paper, the innovative imperatives encapsulated by the government in the notion of the 'harmonious society' which seeks to reduce social inequality through the encouragement of domestic (as well as global) consumption together with a series of social welfare initiatives, have largely failed to address the growing disparity between urban and rural labour markets or the gaps between talent demand and supply.

However, recovery from the GFC does not necessarily imply that such strategies will be sufficient to cope with the long-term challenges posed by China's growing and seemingly intractable talent management dilemmas. In many ways, its remarkable 
economic growth may suggest that in fact it may become a victim of its own success. As the paper has demonstrated, there is an escalating demand for talent as the engine of its present and future development which remains unmatched by the prevalent available supply. On the demand side, there are significant deficiencies in both the quantity and quality of talent, in the information technology, financial and accounting services, real estate, construction, legal and professional services sectors; related to a lack of graduate work experience, limited knowledge of the global business environment, inadequate English language skills, deficiencies in leadership and managerial competencies; and a general failure of the Chinese educational system to develop innovative, creative, or critical analysis capabilities. These talent characteristics are compounded by the inflated expectations of potential employees, influenced both by the 'little emperor' syndrome consequent of the 'one child' government policy and by the global 'Gen Y' phenomenon. They are also reflected, and exacerbated by, the 'compensation creep' experienced in major Chinese cities such as Beijing and Shanghai in recent years.

However, different industry sectors and organizational types have experienced these problems in varying ways. Both local Chinese and foreign multinationals have been less affected than their domestic or SME counterparts due to their abilities to attract and retain some of the necessary talent from a variety of sources (home, host, or third country nationals) and therefore to retain them in the face of intense global competition. However, government bodies, local industries, and small private companies have been less successful in this regard.

On the supply side, in spite of the government's attempted reform of higher and vocational education and industry links discussed earlier, the patchy responses of industry to these imperatives, together with the continuing theoretical (rather than practical) emphasis of the country's universities and the associated questionable quality of their graduates, has to a large extent, stymied the achievement of the desired outcomes. From a Chinese industry perspective, there has been inconsistent involvement in the government's vocational education initiatives both within and between sectors. Thus, whilst there has been some cooperation in employer VET programs, especially amongst the former SOEs, 
and larger private employers have sometimes committed themselves to ongoing and effective human resource development programs; integrated employee development programs have often been circumvented through the utilization of outsourcing and talent poaching imperatives. More strategically focused employers, principally the foreign and local multinationals, have invested in tailored applicant screening techniques; and comprehensive talent development programs, involving employee coaching and mentoring, extensive and customized rewards and career management, and succession planning, in order to attract and retain the talent required to achieve their corporate goals. Such strategies are inextricably linked to the urgency of their needs, the extent of funds available for such purposes, and the long-term orientation of their senior managers.

Thus, in response to the research propositions explored in this paper, the following conclusions are evident. First, the central role of the government in the economy, and its esoteric and pragmatic ideology (the so-called 'third way') and strategies assisted in China's rapid response to the GFC. Second, its cultural traditions and long-term focus ensured the maintenance of subsequent economic growth, albeit with increasing inequalities between urban and rural employees, and between low- and more highlyskilled occupations. Finally, the urgent talent management challenges posed by its rapid economic growth and associated globalization may not be able to be as easily resolved or as amenable to the long-term planning traditions for which China is recognized. Whilst 'building for the future' is an admirable pursuit in both economic and human capital planning terms, its implementation and outcomes in Chinese government and private sector responses to the looming talent management challenges remain problematic.

\section{Limitations and future research}

This paper provides an overview of the breadth and depth of the talent management challenges facing China from a conceptual perspective, with particular reference to the short-term effects of the GFC, and the longer-term implications of recovery and future growth. It contributes to the literature by exploring the specific causes of these challenges in the dynamic Chinese context, and by highlighting the approaches which foreign and 
indigenous MNCs, and local SMEs have adopted to address them. It is limited by an absence of empirical data which would complement or critique such analyses.

\section{Implications}

Future researchers may find it useful to explore in more depth the nature of such talent management challenges and their resolutions in particular industry sectors and/or government versus private industry contexts from the perspectives of former SOEs, Chinese private companies, foreign and local multinationals. Such studies, whether as surveys, case analyses, or combinations of both, would undoubtedly provide invaluable insights into the application of Chinese traditions and perspectives to such contemporary HRM issues.

\section{Notes on contributor}

Alan R. Nankervis has been an HRM academic at universities in Sydney, Perth and Melbourne over more than twenty five years, together with brief periods in Singapore, Hong Kong, Thailand, China, Canada and the UK. His research interests are in performance management and firm effectiveness, comparative Asian HRM, and talent management. 


\section{References}

Ananthram, S., 2011. Talent management philosophies and practices in the Chinese multinational corporations. 12th SGBED Conference. Singapore.

Anonymous, 2005. The changing face of management in China. Available from: www.knowledge.wharton.upenn.edu/article.cfm?artilceid=1164.

Arkless, D., 2007. The China talent paradox. China-Britain Business Review, 14-15.

Beechler, S. and Woodward, I.C., 2009. The global "war for talent". Journal of International Management, 15(3), 273-285.

Bhatnagar, J., 2008. Managing capabilities for talent engagement and pipeline development. Industrial and Commercial Training, 40(1), 19-28.

Bradford, 2007. Training for success in emerging markets: Innovative HR a key to unlocking Far East success. Strategic Direction, 23(9), 36-38.

Cai, W. and Klyushina, U., 2009. Talent retention and development within multinational company in China. Baltic Business School. Masters thesis.

Chatterjee, S. R. and Nankervis, A.R., 2007. Asian management in transition: emerging themes. Basingstoke, U.K: Palgrave.

Chen, H. , 2006. Recruitment and Selection in China: an application to the case of Lenovo, University of Nottingham. MA in Management thesis.

Chen, M. J. and Miller, D., 2010. West Meets East: Toward an Ambicultural Approach to Management. The Academy of Management Perspectives, 24(4), 17-24.

Cooke, F. L., 2010. The changing face of HRM in China. The changing face of Chinese management. In: C. Rowley and F. L. Cooke. London: Routledge.

Cooke, F. L., 2012a. Competition, strategy and management in China. London: Routledge.

Cooke, F. L., 2012b. The globalization of Chinese telecom corporations: strategy, challenges and HR implications for the MNCs and host countries. International Journal of Human Resource Management, 23(9), 1832-1852.

de Haan, A. D., 2010. The Financial Crisis and China's "Harmonious Society". Journal of Current Chinese Affairs, 39(2), 69-99.

Downing, J., Rouleau, W., and Stuber, S. 2008. The war for talent in China. Kellogg School of Management.

EIU, 2010. A better life? The wants and worries of China's consumers. The Economist.

Farrell, D. and Grant, A.J., 2005. China's looming talent shortage. The McKinsey Quarterly, 4(56), 70-79.

Ferguson, N., 2010. Middle Kingdom re-emerges to claim its place on global stage. The Weekend Australian, 21.

Ghosh, J., 2010. Poverty reduction in China and India: Policy implications of recent trends. New Delhi, Centre for Economic Studies and Planning, School of Social Science, Jawarharlal Nehru University.

Haier, 2009. Available from: www.eng.hi138.com/?i8010196.

Holz, C., 2005. China's Economic Growth 1978-2025: What We Know Today about China's Economic Growth Tomorrow, 2 Nov. 2005. Hong Kong, Social Science Division, HKUST.

Huang, Y., 2008. Capitalism with Chinese characteristics: Entrepreneurship and state during the reform era. New York: Cambridge University Press. 
Huawei, 2011. Huawei's Culture. Internal documents.

Iwasaki, Y., 2010. Lessons from PRC and India. Resurging Asian Giants: Lessons from the PRC and China, 1-40.

Kuczera, M. and Field, S., 2010. Learning for Jobs: OECD reviews of vocational education and training: Options for China. OECD.

Leininger, J., 2007. Recent compensation and benefits trends in China. The China Business Review, 34(4), 28-30.

Lenovo, 2010a. 2009/2010 Annual Report Lenovo: The future is ours. US.

Lenovo, 2010b. Sustainability for the next generation 2009-2010: CSR Report. US.

Liu, Y., 2010. Reward strategies in Chinese IT industry. International Journal of Business_and Management, 5(2), 119-127.

Michaels, E.,Handfield-Jones, H. and Axelrod, B. 2001. The war for talent. Boston: Harvard Business Press.

Nacsa, 2011. ICT top 100 in Mainland China, and \#1 Huawei. Retrieved 18 October, 2011. Available from: www.lazure2word/press.com/2011/06/04ict-top-100-inmainland-china.

Nankervis, A. R., Cooke, F.L., Chatterjee, S.R., and Warner, M. 2012. New models of HRM in China and India. London: Routledge.

Pan, C. G. and Lou, W., 2004. Study on situation and development for Chinese talents. The report on the development of Chinese talents. In: C. G. Pan and L. Wang. Beijing, Social Sciences Academy, 1.

Rowley, C. and Cooke F.L. eds., 2009. The changing face of management in China. London: Routledge.

Rowley, C. and Warner, M., (2010). Managers, markets, and the globalized economy in China. Asia Pacific Business Review, 16(3), 483-491.

Sainsbury, M., 2011. Labour shortages a headache for China. The Weekend Australian, 34.

Schuler, R., Jackson, S., and Tarique, I. 2010. Global talent management and global talent management challenges : Strategic opportunities for IHRM. Journal of World Business, 1-13.

Selvaretnam, S. V., 2011. Lenovo: Eye on talent. Retrieved 27 April, 2011. Available from: www.hrmasia.com/site-search/lenovo-eye-on-talent/83154.

Sharma, R. and Bhatnagar, J., 2009. Talent management-competency development: key to global leadership. Industrial and Commercial Training, 41(3), 118-132.

Stahl, G., Bjorkman, I., Farndale, E., Morris, S., Stiles, P., Trevor, J. And Wright, P. (2007). Global talent management: How leading multinationals build and sustain their talent pipeline. INSEAD Faculty and Research_Working Papers, 24.

Teagarden, M. B. and Cai, D.H., 2009. Learning from Dragons who are Learning from Us: Developmental Lessons from China's Global Companies. Organizational Dynamics, 38(1), 73-81.

Warner, M. and Goodall, K., 2010. Management training and development in China: Educating managers in a globalized economy. London: Routledge.

Warner, M. and Rowley, C., 2010. Chinese management at the crossroads: setting the scene. Asia Pacific Business Review, 16(3), 273-284. 
Warner, M. and Zhu, Y., 2010. Labour and management in the People's Republic of China: seeking the 'harmonious society'. Asia Pacific Business Review, 16(3), 285-298.

Wooldridge, A., 2010. The world turned upside down. The Economist (A special report on innovation in emerging markets). Viewed at: http://www.economist.com/node/15879369

Xin, K. and Pucik, V., 2006. Competing through people: Learning from China. Switzerland: IMD.

Yidan, L., 2009. Strategic plan for Haier's global brand building. Mikkeli University of Applied Sciences. Viewed at: http://publications.theseus.fi/handle/10024/5764 .

Zhao, Y., 2009. Haier Group's success strategies. Journal of Human Resources, 9(2), 10- 19. 